\title{
New Insights into Unethical Counterfeit Consumption
}

\begin{abstract}
Consumer demand for counterfeit luxury brands is unethical, but it is also robust and growing. The aim of this exploratory research, which employs in-depth interviews, is twofold: 1) to identify the psychological and emotional insights that drive and result from the consumption of higher involvement counterfeit goods; and 2) to uncover the coping strategies related to unethical counterfeit consumption. This research reveals new psychological motivations (e.g., "thrill of the hunt", being part of a "secret society" and genuine interest) underlying counterfeit consumption and the associated emotional outcomes (e.g., embarrassment, shame and positive hedonic gains). This research is also one of the few studies to identify cognitive moral logics by disclosing the neutralization techniques (specifically denial of responsibility and appealing to higher loyalties) that consumers adopt to cope with the cognitive dissonance associated with debatable counterfeit consumption. The paper contributes to scholarly, managerial and policy conversations.
\end{abstract}

Keywords: Counterfeit; Luxury Brand; Consumer Ethics; Motivation; Moral Logics; Neutralization. 


\section{New Insights into Unethical Counterfeit Consumption}

\section{Introduction}

The counterfeiting of branded products is not new; however, it has only become a significant global problem in its own right in the last three decades (Bian \& Moutinho, 2011b). Despite companies, national governments, and enforcement agencies devoting substantial resources to tackling this issue, counterfeiting appears to be increasing at a faster pace than ever before (Wilcox, Kim, \& Sen, 2009). The International Anti-Counterfeiting Coalition (2014) projected that the value of global trade in counterfeiting and piracy in 2015 would be $\$ 1.77$ trillion. Luxury brands alone lose more than $\$ 12$ billion every year to counterfeit competitors (International Chamber of Commerce, 2004). Consumers' demand for counterfeits, particularly in the luxury goods market, is one of the leading causes of the apparent upsurge in the growth of the counterfeiting phenomenon (e.g., Ang, Cheng, Lim, \& Tambyah, 2001; Bian \& Veloutsou, 2007; Gentry, Putrevu, Shultz, \& Commuri, 2001; Nia \& Zaichkowsky, 2000).

Prior studies have primarily investigated why consumers would knowingly purchase counterfeit luxury brands, and they identify a large number of determining factors that influence consumers' appetite for counterfeits (see Eisend \& Schuchert-Güler, 2006 for a review). These studies enhance our knowledge of the antecedents of the motivational drivers for purchasing and consuming counterfeits. Nevertheless, the literature concerning counterfeit consumption suggests the following: 1) despite the obvious financial drive and various identified antecedents of the motivations, there is a limited understanding of the motivations underlying counterfeit consumption (Jiang \& Cova, 2012; Tang, Tian, \& Zaichkowsky, 2014; Zaichkowsky, 2006); 2) no known study has documented the cognitive processes by which consumers cope with any feelings of unease during counterfeit 
consumption. Purchasing counterfeits is against consumer ethics and is socially undesirable, which inevitably produces some cognitive dissonance (as proposed by Eisend \& SchuchertGüler, 2006); and 3) the prior research to date principally explores counterfeit consumption by applying surveys or experimental methods. Surveys and experiments can prove to be problematic when investigating socially undesirable or self-revealing behavior (Crane, 1999), of which counterfeit consumption is an example. A deeper inquiry of a more interpretive nature is more suitable for revealing as yet submerged motivations and cognitive processes (Malhotra, 2007). This study adopts an in-depth interview method to address these specific issues.

A comprehensive understanding of consumers' motivation to knowingly purchase counterfeits is crucially significant as "motivations produce" outcomes, and they concern all aspects of activation, purchase intention and behavior (Ryan \& Deci, 2000, p. 69). Studies by Wilcox et al. (2009), Perez, Castaño, and Quintanilla (2010) and Jiang and Cova (2012) specifically examine the socio-psychological aspects of motivation for counterfeit consumption. Building on this momentum the current research probes more deeply into the nature and role of the motivational factors in response to calls for further research in this important but underexplored area (e.g., Tang et al., 2014; Zaichkowsky, 2006).

Counterfeit consumption violates laws and consumer ethics, thus raising ethical concerns (Garcia-Ruiz \& Rodriguez-Lluesma, 2014). The construction of counterfeit decision-making in isolation from the moral/ethical aspect hinders our understanding of consumers' demand for counterfeits. This research is one of the few studies to investigate and disclose the cognitive moral logics and the prominent interplay between the motivational drivers and neutralizations (Sykes \& Matza, 1957) underlying unethical counterfeit consumption. Taken together, this current research provides deeper insights into the causes of consumers being prone to counterfeits from a theoretical perspective, thus contributing to 
both the counterfeit consumption literature and the consumer ethics literature. From a managerial perspective, the findings from this research could help marketing practitioners and policy makers alike to establish more refined, effective and actionable counter strategies.

First, this paper presents an overview of the counterfeiting-related research, followed by an outline of the interpretive methods employed to address the research objectives. Subsequently, the research findings are presented. This paper concludes with a discussion of the theoretical and practical implications and suggestions for future research.

\section{Literature}

\subsection{Definitions and Scope}

Product counterfeiting can be easily confused by both researchers and practitioners with imitation and piracy (Bian, 2006). Thus, a clear definition of counterfeiting is crucial (Hoe, Hogg, \& Hart, 2003; Phau, Prendergast, \& Chuen, 2001). Consistent with Chaudhry and Walsh (1996), this research defines counterfeits as products that bear a trademark that is identical to, or indistinguishable from, a trademark registered to another party and that infringe the rights of the holder of the trademark. This definition, which is congruent with the views of both practitioners and researchers, is widely adopted in prior studies (e.g., Bian \& Moutinho, 2009, 2011a; Kapferer, 1995). A counterfeit is a direct copy, whereas an imitation is an indirect copy (Bamossy \& Scammon, 1985), such as imitation smartphones (Liao \& Hsieh, 2013). Imitation is subtle and is often based on partial differences: imitators recreate an overall similarity, even if the details of the packaging differ between the well-established brand and the imitator's own-label product (Kapferer, 1995). In contrast to counterfeiting (which breaches trademarks), piracy infringes copyrights and patents (Chaudhry \& Walsh, 1996), such as music and software piracy (Bhal \& Leekha, 2008; Wan, Luk, Yau, Tse, Sin, Kwong, \& Chow, 2009). From a legal perspective, both counterfeiting and piracy are illegal 
by legislation, whereas imitation does not necessarily break the law unless it is proved to have caused confusion among consumers (Bamossy \& Scammon, 1985).

Counterfeiting is further delineated as 1) deceptive counterfeiting (Grossman \& Shapiro, 1988) (i.e., the consumer is unaware - this form of counterfeiting often applies to low involvement goods); 2) blur counterfeiting (Bian, 2006) (i.e., when they consider purchases, consumers are not sure whether products are genuine, counterfeit, genuine but from a parallel import arrangement, genuine but on sale, or even stolen merchandise); and 3) non-deceptive counterfeiting, in which consumers knowingly purchase counterfeits (Grossman \& Shapiro, 1988).

The present research investigates non-deceptive counterfeiting, which is particularly prevalent in luxury brand markets (Nia \& Zaichkowsky, 2000). Consumers often consciously and willingly access discrete retailers to obtain these counterfeits. The choice of nondeceptive counterfeiting for higher involvement goods as a context is important because the possibility of uncovering psychological motivations and cognitive coping strategies is far more likely. If the counterfeiting is deceptive, then the consumer will not consciously choose a counterfeit over the genuine brand. Consequently, cognitive dissonance and the motivation for buying lower involvement counterfeit goods (e.g., domestic cleaning products) are likely to be less strident, less relevant and less visible to the researcher.

\subsection{Effects of Counterfeiting and Consumer Consumption Appetites}

Counterfeiting has a significant influence on four stakeholders: consumers, legitimate manufacturers, brand owners, and society as a whole (Bian, 2006). Although some studies have suggested that counterfeits could benefit the original brand (e.g., Bekir, El Harbi, \& Grolleau, 2013; Romani, Gistri, \& Pace, 2012), a large body of extant literature argues that counterfeiting is a serious economic, social, and security problem because 1) counterfeiting 
affects consumers' confidence in legitimate products, destroys brand equity and damages companies' reputations, which leads to the loss of revenue (Bian \& Moutinho, 2011a; Commuri, 2009); 2) counterfeiting increases the costs associated with attempting to contain infringement, thus impacting hundreds of thousands of jobs (Wilcox et al., 2009); 3) counterfeiting might also threaten consumer health and safety (International Chamber of Commerce, 2013); and 4) in some cases, the profits generated from counterfeits might be used as financial support for terrorism (Playle, 2003). In most countries, including China and the US - the two main producers of counterfeits in the world - producing and trading counterfeits are criminal offenses (Bian, 2006).

The detrimental effects of counterfeits are often well communicated to consumers. Consumers, therefore, are most likely aware of the damage caused by counterfeits as well as the ethical issues and the violation of the social order involved in counterfeit consumption (Nia \& Zaichkowsky, 2000; Nill \& Schultz, 1996). The intentional purchase of counterfeits is regarded as consumer misbehavior and unethical consumption (Penz \& Stöttinger, 2005). Prior studies, however, report that consumers are inclined to knowingly purchase counterfeits, particularly in the luxury goods sector (e.g., Nia \& Zaichkowsky, 2000; Wilcox et al., 2009). More worryingly to practitioners, the world has seen a steady and rapid increase in the demand for counterfeits in recent years (Bian \& Veloutsou, 2007; Bloch et al., 1993; Phau et al., 2001; Tom, Garibaldi, Zeng, \& Pilcher, 1998), together with increased accessibility to and quality improvement of counterfeits (Wilcox et al., 2009). On the one hand, consumers acknowledge the harm that counterfeits can cause and the unethical nature of counterfeit consumption, while on the other hand, consumers are motivated to buy counterfeits when they are available (Bian, 2006; Eisend \& Schuchert-Güler, 2006; Hoe et al., 2003). Such a misalignment between ethical standards and behavior inevitably results in cognitive dissonance (Eisend \& Schuchert-Güler, 2006). Thus far, the literature has inadequately 
accounted for consumers' coping strategies in explaining how the discrepancies between the unethical nature of counterfeit consumption and purchase motivation are sustained; this gap is one of the focuses of this paper.

\subsection{Motivations for Counterfeit Consumption}

The market for counterfeits can be attributed to consumer demand (Bian \& Veloutsou, 2007; Nia \& Zaichkowsky, 2000; Wee, Ta, \& Cheok, 1995); consequently, a large body of research has investigated why consumers knowingly purchase counterfeits. Prior research identifies many factors that influence the demand for counterfeits. Eisend and SchuchertGüler (2006) classify these influential factors into four broad categories, including person (e.g., demographic and psychographic variables), product (e.g., price and product attributes), social and cultural context (e.g., cultural norms), and situation (e.g., at home versus on vacation). A number of recent papers also investigate the determinants of counterfeit purchasing and find some new influential factors, for example, counterfeit purchase experience (Bian \& Moutinho, 2011a; Kim \& Karpova, 2010), personality and value consciousness (Furnham \& Valgeirsson, 2007; Kim \& Karpova, 2010; Phau \& Teah, 2009), perceived social power (Bian, Haque, \& Smith, 2015), beliefs about counterfeit purchases (Furnham \& Valgeirsson, 2007), perceived risk (Bian \& Moutinho, 2009; Tang et al., 2014), product appearance (Kim \& Karpova, 2010), product involvement (Bian \& Moutinho, 2009),

product utility (Poddar, Foreman, Banerjee, \& Ellen, 2012; Tang et al., 2014), product conspicuousness (Bian, Haque, \& Smith, 2015), brand personality (Bian \& Moutinho, 2009), perceived company citizenship (Poddar et al., 2012), and social influence (Phau \& Teah, 2009; Tang et al., 2014). All of these factors are readily compatible with the four categories suggested by Eisend and Schuchert-Güler (2006). 
Studies addressing why consumers knowingly purchase counterfeits have increased our knowledge of the factors affecting counterfeit consumption behavior. These identified influential factors, in particular, mainly represent the antecedents of motivations for counterfeit purchasing propensity rather than the motivations themselves. For example, perceived risk is a type of perception, rather than a motivation, which can activate the motivation for risk avoidance. By definition, perception is the belief and interpretation of sensory information (Assael, 2004), whereas motivation is "an activation, an incentive or a reason to start or maintain behavior" (Antonides \& van Raaij, 1998, p. 164). Indeed, several recent studies emphasize that a clear and actionable understanding of the motivational drivers for consumers' counterfeit purchases remains elusive (e.g., Jiang \& Cova, 2012; Tang et al., 2014; Zaichkowsky, 2006).

Responding to calls for research investigating the motivational drivers of counterfeit consumption (Zaichkowsky, 2006) and drawing on the functional theories of attitudes (Katz, 1960; Shavitt, 1989; Smith, Bruner, \& White, 1956), Wilcox et al. (2009) demonstrate that consumers' desire for counterfeits hinges on their social motivations, for example, to express themselves and/or to fit in. Specifically, consumers' preferences for counterfeits and the subsequent negative changes in their preferences for the genuine brand are greater when their genuine brand attitudes serve a social-adjustive, rather than value-expressive, function. In the same vein, Perez et al. (2010) and Jiang and Cova (2012) also reveal that the consumption of counterfeits allows consumers to construct a desired social identity.

These researchers advance our understanding of consumers' social motivations for purchasing counterfeits by going beyond the obvious financial incentives. Social drivers, such as the desire to create and sustain ideal identities, are the focus of the aforementioned studies, thus representing motivations based on external regulation. Adopting a qualitative research method, which is a more appropriate approach for exploring psychological 
motivations and the associated cognitive processes, the present research aims to explore the prominent motivations that guide consumers' propensity for counterfeit consumption and to uncover the coping strategies that consumers employ to justify their behavior. With the increasing sales of counterfeits worldwide today, a more comprehensive understanding of the motivational drivers behind counterfeit consumption, combined with the unethical and/or socially undesirable nature of such behavior and the important but largely overlooked underlying mechanisms of counterfeit consumption propensities will significantly contribute to the rapidly growing counterfeit and consumer ethics literature. Specifically, this study addresses the following important questions that have not yet been fully explored:

1. What are the motivational factors (e.g., intrinsic motivations) that are not comprehensively revealed by previous research?

2. How do consumers cope with the cognitive dissonance generated by their unethical counterfeit consumption behavior?

3. Are consumers immune from psychological concerns and what are the emotional outcomes associated with consuming luxury brand counterfeits?

\section{Methods}

Given the exploratory nature of the study, a qualitative approach is applied that is oriented toward discovery. Qualitative research, which is contextualized, considers the different characteristics of the context in which the data collection occurs (Belk, Fischer, \& Kozinets, 2013). Therefore, to identify the motivational factors that might influence consumers' decisions when purchasing luxury-branded counterfeits together with the cognitive process that consumers adopt in justifying such behavior, this study employed indepth interviews for data collection. In-depth interviews are "directed towards understanding informants' perspectives on their lives, experiences, or situations as expressed in their own 
words" (Taylor \& Borgan, 1984, p. 77). Thus, this method helps to infuse meaning (Silverman, 2011) into consumers' shopping activities regarding counterfeits by allowing the respondents to talk about their experiences in an ideographic and natural manner (Hirschman, 1986).

This study chose the Chinese marketplace as the context because China is both the largest producer (International Anti-Counterfeiting Coalition, 2014) and the largest consumer of counterfeit products (Cheung \& Prendergast, 2006). Twenty percent of domestic sales in China are of counterfeit products (Swike, Thompson, \& Vasquez, 2008). Counterfeits are so widely available in China that these products even have their own dedicated shopping areas (Lin, 2011), such as the Silk Market in Beijing.

The recruitment plan was purposive to provide the researchers with an informationrich sample. The intention was to discover relevant and rich, rather than representative, information regarding the research questions (Patton, 1990). The researchers therefore purposefully searched for participants who were from China and who had either purchased counterfeit products and/or who knew someone else who had. The purchase of counterfeits is a topic that is self-revealing and therefore sensitive. Thus, ensuring individuals to converse and engage with the research is the key to the success of this study. Before the interviews started, the participants were told that a large percentage of consumers knowingly purchase counterfeits, including consumers in developed countries, such as the UK and the USA. The aim of this information was to encourage participants to provide truthful information because this technique can induce a respondent's admission of potentially embarrassing behavior (Churchill, 1999). During the interviews, participants were ensured by the researcher that anonymity will be kept to whatever they say. The participants were encouraged to talk first about their own purchase behaviors and experiences, and then they were probed to discuss others' counterfeit behavioral tendencies and experiences. The latter was added in case the 
respondents felt uneasy discussing buying counterfeits due to potential legal/ethical considerations, and in order to provide further anonymity to whatever was discussed during the interviews. This research recruited respondents using the snowball recruitment method (Browne, 2005) by asking the interviewees to recommend friends who might have also purchased counterfeits.

The researchers conducted sixteen in-depth interviews (one-to-one) with Chinese consumers. The interviewees' profile is quite varied in terms of demographics and behavioral characteristics. They are of both gender and their age range is from 18 to 35 years old. They also come from varied educational and economic background. Our main interest was on participants having experience with counterfeits, that is having bought at least once such products. Further details about participants' profile as well as the type of counterfeit products they had had experience with can be found in Table 1.

\section{(Insert Table 1)}

The interview guide used consisted of four main sections, as seen next along with some sample questions in each case. The first section included questions on consumer behavior in general, and consumer behavior of luxury brands in particular, i.e. Do you buy luxury products? What kind of products do you prefer buying? Do you happen to have any preferred brands? How often do you buy them? For who do you usually buy them? The second section had questions on consumer behavior and perceptions of counterfeits, by asking interviewees to talk about occasions where they have bought counterfeits, i.e. Have you ever purchased any counterfeits? Could you please walk me through such a purchase? Can you talk more about your experience of buying the counterfeit? How did you feel when you buy it? What about some time afterwards? Have your thoughts changed? Do you happen to have any other example(s)? Could you please elaborate on it? The third section involved questions on the consumer behavior and perceptions of counterfeits of the interviewees' 
friends i.e. Do you happen to know if any of your friends are buying or have bought counterfeits? Were you with them when they bought it? Did they ever tell you what they had bought? Why do you think they bought it? What did they say at the time? Have you seen them using the product? Have they changed their mind since? The fourth section looked into the comparison of perceptions between counterfeit and authentic products, i.e. What is the relationship between counterfeit and authentic brands? Do you think that it will change in the future?

The interviews were conducted by a Chinese native speaker experienced researcher of similar to interviewees' profile, in order to make them feel more comfortable in sharing sensitive information and without worrying of how they might be perceived. The interviews lasted from 25 to 65 minutes and were audio-recorded. They were then transcribed to Chinese by substituting participants' names to coded numbers, in order to further ensure anonymity, and translated to English. The translation was double checked by one of the authors who is Chinese native speaker. Next, they were, analyzed using the interpretive thematic analysis technique, in which pattern recognition was used in an effort to "construct a representation of meanings as recurring themes producing an interpretation of interpretations" (Spiggle, 1994, p. 499). Interpretive, qualitative research examines richly detailed data rather than quantifiable data (Belk et al., 2013). As a result, the emergent themes presented below serve to provide a contextual understanding of social behavior from the perspective of the consumer (Flick, 2007), and they do not constitute "factual" data as such (Spiggle, 1994). The interviews were conducted until thematic saturation was achieved.

\section{Results}

The analysis led to the generation of three primary themes relating to unethical counterfeit consumption and purchase behavior: 1) motivations and coping strategies as well 
as the interplay between the motivations and neutralizations of the behavior; 2) consumer hierarchy based on brand confusion and consumer expertise in counterfeits; and 3) risk, rewards and self-conscious emotions. There were also a number of secondary themes, all of which are discussed below.

\subsection{Motivations and Neutralizations}

As previously described, the extant research sheds light on the motivational antecedents for counterfeit consumers; however, the literature does not account well for the psychological aftermath (motivation and act/post-act rationalization are inextricably linked but are potentially dissonant) and cognitive process. This study systematically reveals the primary motivations of consumers and their coping strategies as well as the interplay between motivations and rationalization, specifically neutralization (Sykes \& Matza, 1957).

All of the respondents could readily account for their desire for luxury brands or could provide accounts of their associates' preoccupations with such brands. This desire appears to be a function of the aspirational and social comparison drivers internalized by external regulation, which are common in rapidly developing economies, consistent with Wilcox et al. (2009). Some respondents were conscious of the harm to the brand being copied, while others expressed little concern, and some even argued that counterfeiting is good for the brand being copied, almost as if the illegal counterfeit industry is paying the brands a compliment or is promoting the legitimate brands (although such responses might be evidence of consumer neutralization - Chatzidakis, Hibbert, \& Smith, 2007 - or of rationalization of ethical transgression). In short, the responses varied between the following extremes.

“...because it is stealing the LV design, I wouldn't buy it. If they can produce purses with such good quality, why don't they just hire a designer and make their own brand?" (Female, age 26) 
"She wanted a purse. She went to Hong Kong, where the authentic purses were cheaper but were still expensive. She didn't want to pay that much, but she really liked the purse. So she bought a counterfeit. The seller said the leather was the same, and everything was the same. The only difference was the factory. Then my mother bought it at a lower price, and she thinks it was a good deal." (Female, age 28)

It is worth noting that the respondents rarely mentioned the other possibility, which is buying a less expensive alternative brand, which shows that luxury brands or their counterfeits are seen as "essential" items for the cohort, thus providing further evidence of the salient power of luxury brands for the contemporary consumer. A pervasive attitude could be characterized as follows: if a good facsimile can be acquired less expensively, then why not take the opportunity? The obvious justification for purchases is economic, that is, saving money, as previous research suggests. However, the data also provide ample evidence of other motivations, both extrinsic and intrinsic. This research identifies that the underlying extrinsic motivations for purchasing are the self-image enhancement of luxury brands, and the prominent intrinsic motivations include a sense of interest and hedonic impacts of the act of attainment (e.g., "the thrill of the hunt" and being part of a "secret society" - see below). There was a strong sense in some of the interviews that Chinese consumers see counterfeit goods as a form of "legitimized" competition or as simply another choice in a crowded marketplace, almost as if counterfeits are offshoots of the actual brand, although this perspective might be another neutralization strategy. Consumers acknowledged that counterfeit product offerings rely on the authentic products, yet they appeared to accept the thesis that counterfeits co-exist with authentic products.

"My mother told her friends that she went to a place and she bought some counterfeits. If people ask me, I would tell them it is a counterfeit. I would even take them to the place if they want. I would not pretend that I am carrying the authentic product if it is not." (Female, 
age 28)

The above response might be a function of the location of a substantial illegal counterfeit industry in China that seems to create a consumer norm (although it should be noted that the counterfeit market is global). This apparently pervasive norm seems to facilitate rationalization using the neutralization techniques described below. If something is normalized, then justification of the behavior is made easier.

"In China, everyone carries a LV purse; even the women selling vegetables in markets carry LV purses. Everyone on the subway has an LV purse, and you know that none of them is authentic. This phenomenon degrades the reputation of LV." (Female, age 28)

"On a rainy day, the person that uses his bag to cover his head means he is carrying a counterfeit, and the person that covers his bag by their body means he is carrying an authentic one." (Female, age 22)

Some of the respondents claimed that they are above the symbolism and semiotics of brands altogether; therefore, they stated that their purchases are a function of their own autonomy as a consumer and individual, thus portraying themselves as knowledgeable, rational and wise consumers whose consumption behavior is mainly guided by consciousness of value.

“...these jeans are so expensive in China, they're selling between three hundred to one thousand RMB, but you could buy counterfeits everywhere for only one hundred RMB. I don't really care if it's authentic or counterfeit; all I want is that kind of trousers. I don't feel any difference between the one with a logo and the one without a logo. I think most of them are counterfeits." (Male, age 25)

Although acknowledging the illegal nature of the counterfeit trade, some consumers are nevertheless prepared to go to great lengths to obtain counterfeit goods; the primary extrinsic motivation is the attendant impact on self-image of being in possession of "must- 
have" luxury items, whereas the subordinate motivation is the economic gain associated with counterfeit purchases.

"I will buy a product that helps me to achieve high social status...It saves you money, more designs, more choices, and gives you satisfaction.” (Male, age 29)

This study further discovers that "the thrill of the hunt" associated with counterfeit purchases is a pronounced intrinsic motivation. The revealed substantial dimensions include strong emotions and adventure. Participants appeared to value the plethora of choices offered in counterfeit shops, which seemed to add excitement to the overall shopping experience.

“...Girls know what they want, for example, conspicuousness of logo, color, style, size and so on. Very detailed. There are so many of them. Guaranteed some of these products will meet your requirements. You can then choose among them.” (Female, age 27)

"She told me she bought a cell phone that looks like iPhone. The one she bought is gold; however, an authentic iPhone is only either black or white. You could get those fake iPhones either through online or a shopping channel on TV. When calling to place the order, she was asked whether she wants her phone in gold or pink. There were five options. In addition, they [counterfeit sellers] offer personalizing services on the phone and free shipping too. The total cost was only one-fifth of a real iPhone." (Female, age 26)

"There are two types of counterfeit purchasers. One tells you: 'you know what? This LV [purse] cost me US\$200, doesn’t it look real? I think it does, and it's so worthy.' This group of people doesn't really try to cover it up. Perhaps their attitude toward luxury brands is no different from mine. They don't care whether those purses are fakes or not. They don't think it is necessary to spend a huge amount of money on real ones. They will tell you openly about buying low price counterfeits. I like their honesty. However, there is another type of people who don't tell the truth...Frankly speaking, I prefer those who tell the truth. I feel kind of cool when you spend US $\$ 200$ on a counterfeit LV, and we may discuss how great they are 
made in China nowadays, and they make them look so real." (Female, age 25)

Given the illegal nature of the counterfeit market and the adventure involved in discovering well-hidden and often misleading and confusing product offerings, certain consumers tend to be attracted by the complexity and secrecy surrounding the shopping experience. There seemed to be a shared sense similar to that of belonging to a secret community that draws consumers to buy counterfeits, regardless of the level of the counterfeit consumer hierarchy into which they fall. The consumers of counterfeits seemed to take pride in being part of a "secret society."

"Selling counterfeits is illegal, right? So you need access to the sellers, maybe through relatives or friends. You will get a phone number and you call them and ask to see the purses. They will tell you where to meet and bring you to a place to see the purses. It is really secret!" (Female, age 28)

"Most of them are guys, and they don't really care about carrying counterfeits. They think it is interesting and a subject to make fun of. They laugh about original well-known brands and always wear counterfeit famous branded t-shirts. If it is a good deal, I would feel good." (Female, aged 26)

This highly mystical behavior, which is not expected to be experienced in retail shopping, adds a sense of exclusivity, excitement and adventure to the buying process. The hedonic value from the counterfeit consumption support previous research findings that hedonic benefits positively influences counterfeit consumption (Yoo \& Lee, 2009). Moreover, the counterfeit consumption seems to be sacralized through the mystical behavior (i.e., rituals) (Durkheim, 1975). Belk, Wallendorf, \& Sherry (1989) identified six potentially sacred consumer domains: places, times, tangible things, intangible things, persons, and experiences. The counterfeit experience from our informants involves these domains. Specifically, consumers of counterfeits appear to sacralize the transaction markets (places), the 
counterfeits (tangible things), the secret between friends (intangible things), the sellers (persons), and the mystical acquisition process (experiences). Therefore, this feeling of participation in a secret community functions as an additional motivational factor that enriches the shopping experience by evoking strong emotions and social bonds.

The data also provide evidence that neutralization techniques (Sykes \& Matza, 1957) are being employed to excuse unethical counterfeit consumption. Specifically, these techniques are essentially rationalizations that are enacted to ameliorate the negative effects on self-image of engaging in questionable acts or behavior; they also enable the dissipation of any cognitive dissonance (see Eisend \& Schuchert-Güler, 2006). The two most common neutralization strategies are as follows. The first is "denial of responsibility". This a circumstance in which one argues that she/he is not personally accountable for the social norm-violating behavior because factors 'beyond one's control' were afoot (e.g. 'It's not my fault I don't recycle, the local government should make it easier for me by providing a better service (; , "I bought counterfeits because there are so many of them on the marketplace in China;" "I was guided by a friend").

"Yes, I did [purchase counterfeits]. If I'm buying for myself, I don't really care much about brands. Almost every luxury good, except for watches, is made in China, such as clothes, shoes, jewelry. There are so many counterfeits in the marketplace. Sometimes, it is kind of difficult to examine whether it's authentic or not." (Male, age 25)

“I bought a pair of counterfeit sunglasses. Rayban, I think. I didn’t intend to get a pair of [counterfeit] sunglasses; I just wanted a pair of sunglasses. Then my friend took me to a place that sells sunglasses. That was a building with several floors. All of the stores in that building sell sunglasses. She took me to the store she visited before, where Grade A counterfeits were available.” (Female, age 28)

The second most commonly observed technique was "appealing to higher loyalties", 
or adhering to a higher order motivation. It is a circumstance in which one argues that normviolating behavior is the result of an attempt to actualize some higher order ideal or value (e.g. "I'd like to buy more environmentally friendly furniture that isn't made of endangered hard woods but I'm really into design." - here the 'higher loyalty' is the quest for beauty/optimal aesthetics). The most common examples in the data amounted to "I bought it because I liked the product, not because it is a brand;" and "I bought them because they' re cheaper and I am trying to save money;").

“Just like sometimes you don't really go shopping for a specific product, and maybe you don't even bring any money with you, either, but once you see something good or that looks delicious, you want to buy it. And you're buying it not because of its brand. Or maybe you were looking for a purse that probably cost ten thousand RMB, but you found a counterfeit that has the same high quality as an authentic one and only costs you less than one thousand RMB. That will definitely attract you to buy it." (Female, age 20)

“

"That is because, first of all, counterfeits were cheaper (prices were lower). When she just started working, she needed to pay for the rent, along with monthly expenses. So for people like her who just got a job, she could not offer genuine products”. (Female, age 35).

Some of the rationalizations are quite complex and possibly relate to more than one neutralization technique simultaneously. For example the following statements can be seen as examples of "condemning the condemners" (e.g. "They rip us off, they cost too much so why not buy stuff that looks the same?") and "denial of victim" or "even blame of victim". Indeed the first quotation also entails appealing to higher loyalties as well (money saving).

"I think some famous brands like LV and Gucci, they are too expensive. The cost of the purse itself is not that much. They are selling the brands. Therefore, people don't want to spend that much money buying the vanity. So when they think the purse looks good they buy 
the counterfeit." (Female, age 31)

“Actually, I think that the cost of a famous brand purse shouldn't be that high. My

mother just wanted a famous brand purse, which shouldn't cost that much. Then why not just buy a counterfeit?" (Female, age 28)

The data illustrate the rational and deliberative approach to counterfeit buying that was robustly evidenced in the cohort and their associates as a whole. However, such a selfcentered orientation ignores the other effects of counterfeit purchasing (breach of intellectual property rights, exploitation of labor etc.).

\subsection{A Consumer Hierarchy Based on Brand Confusion and Consumer Expertise}

The data revealed many accounts of brand confusion and ambiguity among the nondeceptive counterfeits experienced by consumers when interacting in this particular marketplace. The participants experienced a choice of products that possess similar characteristics, and at the same time, their expectations were fueled by various sources of communication (Hukla, Banerjee, \& Adidam, 2010). This situation creates brand confusion and makes information processing and decision making quite complex and demanding. Brand confusion further increases due to factors such as cognitive dissonance (Mitchell \& Papavassiliou, 1999) and negative word-of-mouth (Turnbull, Leek, \& Ying, 2000), which are related to counterfeit consumption.

"There are still some drawbacks when buying counterfeits because if you are not good at evaluating the product quality, you know the price is always closely related to the quality. Thus, you may worry whether the color will fade over time [given that you have only paid a fracture of the price you normally have to pay].” (Male, age 29)

Therefore, the plethora of similarly appearing products among counterfeit offerings, together with the diverse and often questionable sources of information, makes knowledge of 
the market a highly valued asset. In contrast, some of the respondents, as observed in the analysis, appeared to be expert consumers with an almost forensic knowledge of brands, products, and the counterfeit industry. This extensive knowledge implies that such consumers spend a great deal of time acquiring the market and product knowledge required to be a successful buyer of counterfeit goods. These consumers show genuine interest in counterfeits, which represents intrinsic motivation. These consumers also tend to wield their expertise purposefully.

"It [the counterfeit] could be customized with many options. For example, pick the color you like...the little decoration on the Dior bag makes it even prettier than the authentic one.” (Female, age 24)

"It depends. For example, for LV purses, they have different categories including grade $\mathrm{A}+, \mathrm{A}$, and $\mathrm{B}$. Grade $\mathrm{A}+$ means it is made from the same leather as authentic LV purses, but it is made in another factory, not the authentic LV factory." (Female, age 28)

Consumers possessing this type of expertise about both the authentic and counterfeit products are able to overcome brand confusion among the diverse counterfeit offerings and to form a holistic understanding of the marketplace by successfully comparing and contrasting product features between the different counterfeit products available. Their extensive product knowledge and experience with such offerings place them atop a counterfeit knowledge consumer hierarchy based on the dimensions of brand confusion and consumer expertise. This position signals status and recognition as experts in the subject matter by their peers. Their views carry heavy weight due to the uniqueness and complexity of the particular marketplace. Given the risks involved in such purchases, as will be analyzed in the next section, including the lack of official marketing communications activities and increased brand confusion, other consumers rely heavily on peer-to-peer communication. In addition, this eye for detail was quite pervasive within the cohort and might help to explain the anxiety 
about falling victim to another expert's judgment when in possession of a counterfeit item.

"It is on the lining of the purse. There is a button, and it covers the mark. So you won't notice if you don’t look closely.” (Female, age 27)

Next on the counterfeit knowledge consumer hierarchy is occasional counterfeit consumers who do not have the time or the inclination to undertake much research. They are followed by rare counterfeit consumers or spontaneous purchasers who have bought such products only a couple of times. On the bottom of the counterfeit knowledge hierarchy are first-time counterfeit consumers or consumers who are willing to buy such products in the near future. They also do not possess satisfactory knowledge of the market, and they often follow people who are considered to be word-of-mouth counterfeit experts.

"I've bought counterfeits twice. However, because I like authentic products more, I don't buy counterfeits that often. The first time was that a member of my family accidentally bought a very cheap counterfeit LV wallet. It was only RMB¥10, and it looked like an authentic one. The other time was helping my friend buy an LV counterfeit in Beijing on my way home from Canada to China. The retailers in Beijing had different classes for LV or Gucci counterfeits such as A, B, and C. All I bought were grade A products, so they were also expensive.” (Female, age 31)

This research identified a consumer hierarchy in terms of counterfeit knowledge can function as an additional motivational mechanism for two main reasons. First, consumer expertise helps buyers overcome brand confusion_between the different counterfeit products available and, and as a result, it simplifies their decision-making processes. Second, consumers atop the hierarchy declare and want to retain their position, and at the same time, consumers in the middle or lower levels want to expand and deepen their knowledge and experience about the market to move up a level. In so doing, consumers expect to enhance their self-image because they will be considered by their peers to be knowledgeable and will 
probably be consulted by other consumers from lower levels of the hierarchy who want to purchase such items. In contrast, there are consumers who have no further interest in devoting time and effort into learning in depth this marketplace. Thus, they are contempt in remaining in their existing level in the counterfeit knowledge consumer hierarchy.

"No, not because he saw a lower price [product]. He bought some shoes of better quality before. He was looking for better shoes at the first place, just couldn't find the right design, and then went for counterfeits. If the design is right, he tends to buy better quality ones." (Male, age 29)

The data were also consistent with findings in the existing literature suggesting that brand confusion_could be related to the product category (Foxman, Muehling, \& Berger, 1990; Foxman, Berger, \& Cote, 1992). As observed from the transcripts below, this confusion seems to be related to certain product categories in particular (e.g., cosmetics, eyewear), thus lessening purchase propensity. A consumer could be a confident and savvy buyer of counterfeits for given categories and yet quite timid for others. Therefore, consumers atop the counterfeit knowledge consumer hierarchy in one product category might be on a lower level of the hierarchy in another product category. This product category effect could add to the experienced brand confusion, which was evident throughout the data set.

“... She couldn't afford the authentic ones, and the cosmetics there looked okay. Cosmetics are tricky, you don't really know whether they are authentic or not. There are sellers who sell cosmetics online, and they claim they are selling authentic. They have a big bottle of the skincare and sell them in different bottles. Some people say they are authentic, but some say there are other ingredients added in the separate bottles of it. So it is tricky...I really don't know because unless you used the authentic one before and you can compare it, otherwise how could you know whether it was authentic or not?" (Female, age 27)

"As for watches, I would not consider buying counterfeits if the brands are especially 
expensive. I think that a genuine watch can last for a long time. For sunglasses, personally speaking, I think that genuine products and their counterfeit counterparts look alike in appearance, yet their prices are very different. Maybe it is due to the quality of lenses." (Female, age 35)

In summary, consumer expertise in counterfeits becomes an essential aspect of counterfeit purchases as well as a strong motivational factor due to increased brand confusion among non-deceptive counterfeits, the absence of official marketing communications activities, and the high perceived risks involved, as will be analyzed next.

\subsection{Risks, Rewards and Self-conscious Emotions}

Risks are categorized as either:

1) functional (i.e., poor quality or malfunction); or

2) socio-psychological. Specifically, this type of risk is manifested by damage to the social self-image caused by the experience of self-conscious emotions, that is, embarrassment and, in some cases, shame (see Gregory-Smith, Smith, \& Winklhofer, 2013). This finding is almost the inverse of Wilcox et al.'s (2009) observations about self-image enhancement when people "get away with it." Surprisingly this embarrassment does not appear to be caused by the exposure of an ethical or legal wrong; it has more to do with the exposure of a social wrong (only when caught), that is, “I am a fraud. I'm passing myself off as something I'm not," as opposed to "I am a criminal," or "I am doing something that is unethical." The psychological risks seemed to have much more power over the respondents than the functional risks and constituted the real negative outcomes that counter-balanced the economic and self-image benefits of buying luxury brand counterfeits. Interestingly the data also suggests that when they were facing close relatives or fellow counterfeit consumers the respondents were not concerned about their social self-image. 
"Yes, and it was a counterfeit. I don't want to make people think I am rich, and I don't want to lie to people saying that it is authentic. It is also very embarrassing if I tell them it is a counterfeit." (Female, age 27)

“It doesn't matter. I will tell my family directly that I spent some money buying a counterfeit because no one would look down on me. It makes me embarrassed to let my friends or colleagues know that I bought counterfeits." (Female, age 31)

Positive emotional effects are also apparent. The data disclose that counterfeits can bolster the self-image. If the respondent is able to elude detection (i.e., not be "found out" by peers), then the external image effect is potentially the same as that achieved through the purchase and ownership of the genuine brand. Also when the respondents gave accounts of "getting away with it," they clearly felt self-satisfied for saving money (i.e., "I've saved money, and no one has noticed."). This finding adds to the findings of Wilcox et al. (2009) and is also related to "the thrill of the hunt" concept (Hirschman \& Holbrook, 1982) discussed above because some of the respondents seemed to derive a powerful sense of satisfaction and enjoyment from sourcing quality counterfeits at a fraction of the price of the original. The risk of indulging this positive effect is to be found out or exposed as a buyer of counterfeits. This threat of exposure seems to cause real anxiety, as evidenced by the onset of self-conscious emotions, particularly embarrassment (and shame to some extent). The tradeoff with counterfeits is time over money; that is, finding "quality counterfeits" requires time. Searching for counterfeits seems to have a hedonic (affective/emotional) element in much the same way that bargain hunting of any type is pleasurable.

\section{Discussion}

\subsection{Overview}

Figure 1 summarizes the above identified themes and highlights the previously 
neglected motives of the role of self-image enhancement: "the thrill of the hunt," being part of a "secret society" and a sense of interest. Such initial motivations can occur in any combination, and once enacted, they are often sustained by two neutralization techniques: denial of responsibility and appealing to higher loyalties. Counterfeit consumption, in becoming a norm in society, seems to become legitimized, but it still carries risks (i.e., being found out). The fallout or benefits of the episode depend on whether the item is perceived as a counterfeit by peers. If one's peers discover that the purchase is a counterfeit, then the outcome is essentially emotional (embarrassment and shame) and powerful, and it cannot be reversed by any neutralization. The benefits are economic advantages, an enhanced selfimage, enjoyment or satisfaction (or all four). There are also cases in which consumers purposefully reveal their counterfeit purchasing experiences. This self-declaration of counterfeit purchase behavior is mainly driven by enhanced self-image through demonstrating expertise in counterfeit products and an unconventional manner of thinking and behaving. This behavior is further supported by peer recognition expressed by those at higher levels of the counterfeit knowledge consumer hierarchy, who provide valuable information to less experienced shoppers in overcoming brand confusion.

Insert Figure 1 about here.

\subsection{Theoretical and Marketing Implications}

This research makes significant contributions to the counterfeit consumption literature and the consumer ethics literature. First, this study advances the theoretical understanding of the consumer motivations underpinning counterfeit consumption. Building on previous research, this study identifies new consumer motivations for counterfeit consumption. Specifically, in addition to financial and social-adjustive purposes (e.g., Wilcox et al., 2009), 
this study identifies that self-image enhancement, intrinsic hedonic outputs ("thrill of the hunt" and being part of a "secret society") and a sense of interest are the most powerful motivational drivers of unethical counterfeit consumption. This study further discovers that to achieve self-image enhancement through counterfeit consumption of desirable brands consumers adopt three measures: 1) association with a desirable brand (if not detected), 2) demonstration of extensive product knowledge, and 3) being a rational/wise consumer. These findings indicate that multiple motivational drivers and associated desirable outcomes, rather than only product and personal characteristics ( $\mathrm{Lu} \& \mathrm{Lu}, 2010)$, are key determinants of the consumer-willing counterfeit-consumption link. As consumers seem to take pride in being part of a secret community for counterfeit consumption, this finding extends the research in the sacred and profane in consumer behavior to a new domain-counterfeit consumption (Belk et al., 1989). The mystical experience seem to sacralize counterfeit consumption. In addition, this study is the first which reports a counterfeit knowledge consumer hierarchy based on the dimensions of consumer expertise and brand confusion_among non-deceptive counterfeits. Second, this study also contributes to the understanding of consumers' cognitive processes by providing, apparently for the first time, empirical evidence of the distinct neutralization functions underlying unethical counterfeit consumption, thus enriching the rapidly emerging ethics literature (Audi, 2012). Specifically, this current study reveals two main neutralization techniques in particular that consumers adopt to justify their unethical counterfeit consumption, which include: 1) denial of responsibility and 2) appealing to higher loyalties, to address their cognitive dissonance associated with counterfeit consumption (if there is any) or the discrepancies between their actual behavior and consumer ethics.

Differing from Eisend and Schuchert-Güler's (2006) proposition, this study discloses that in some cases, consumers do not seem to suffer feelings of embarrassment and/or shame due to their deviant counterfeit consumption behavior. Easy access to counterfeits of all types 
accompanied by consumer inclination toward counterfeits in China seems to have normalized counterfeit consumption; as a result, some consumers might not believe that they are doing anything aversive, despite counterfeit consumption being ethically and/or legally wrong. This study is one of the few to emphasize the interplay between motivational drivers and neutralizations (Sykes \& Matza, 1957), thus opening up new avenues for future research in consumer ethics.

Third, this study also adds to the understanding of counterfeit consumption by reporting the possible impact of consumer expertise and product quality ambiguity on counterfeit choice. Apparently, little research has identified such effects. The findings suggest that consumers with a high level of expertise can tell the difference between genuine and counterfeit articles. Consumers tend to use their expertise to their advantage, and they calculate the likelihood of being exposed by peers and the associated social risks against the desired self-image enhancement. Experience products (e.g., cosmetics), for which consumers cannot make judgments about the quality based on appearance, hinder consumers' intentions to purchase counterfeits as consumers are concerned about the quality of such counterfeits.

Fourth, this study unfolds two opposing emotional experiences in counterfeit consumption. Previous research findings have identified the emotions of guilt and regret in unethical behavior (Gregory-Smith et al., 2013). This study, however, notes that the illegal or unethical aspects of counterfeit consumption are unlikely to be concerns of counterfeit owners; that is, social risk does not appear to be caused by the exposure of a legal or moral wrong; rather, social risk has more to do with the social embarrassment associated with being exposed as a deceiver. In contrast, positive emotional output can occur when the hunt for counterfeits brings high quality copies with low costs, when the buyers get away with the purchase, and when peers appraise the buyers for being knowledgeable and wise consumers. The findings of this study provide marketing implications for brand managers and 
useful insights for public policy makers. Given that techniques of neutralization underlie unethical counterfeit consumption, the neutralization strategies employed should be countered through marketing communications. Bersoff (1999) recommends that less ambiguity there is surrounding a situation, the less latitude an agent has in negotiating reality in such a way as to provide justification for an unethical action. Marketing effort, thus, should address identified ambiguity with an aim to lessen neutralizations made available to counterfeit consumers. Based on the findings of this research the focus should be on dealing with denial of responsibility (e.g. wide availability of counterfeits; guidance from other consumers) and appeal to high loyalties (e.g. money saving; down to earth) as they are the two most common neutralizations adopted by consumers of counterfeits. Specific marketing campaign messages could include "if you buy counterfeits undeniably you are accountable for the wide availability of fakes", "no one could force you to buy fakes unless you truly want to", "it only takes one wrong of counterfeits to ruin everything", and "counterfeits are brands, the only difference is that they are fake brands". Focusing on supply chain aiming to reduce availability of counterfeits to the end marketplace is another approach, which might also be effective. Neutralizations facilitate unethical behavior only to the extent the neutralizer believers that his/her rationalizing is likely to be accepted or tolerated by society (Skype \& Matza, 1957). Unethical behavior stemming from neutralizations is a utilitarian-type decision, where potential gains at least compensate losses (Bersoff, 1999). Thus, addressing consumer concerns associated with counterfeit consumption may result in favorable outcomes. For example, the social risks of being "exposed" could be emphasized in anti-counterfeit campaigns. Consumers want to save money, but they want to do so without losing face. Counterfeit consumption comes with risks; the product can fail, or if discovered, the purchase could be judged by peers. These two negative potential outcomes could be exploited in counter-counterfeit communications. The findings that counterfeit purchasers are less likely 
concerned about ethical/legal issues associated with counterfeit consumption also indicate that marketing campaigns that emphasize the legal/moral wrongs of counterfeiting might not provide immediate fruitful results. Policy makers or brand owners need to seek to subvert this attempt to ignore externalities.

\subsection{Limitations and Future Research}

This study has some limitations, but it also provides avenues for future research. Given its exploratory nature, the focus of this study was on achieving understanding, rather than on generalizing (Banister \& Hogg, 2004). The main findings, therefore, must be understood in the context of the study's methodological trade-offs and limitations. This study did not specifically examine the product categories of counterfeits. Future research could be based on experimental studies investigating the impact of specific product categories and product information ambiguity on counterfeit consumption, and experimental methodologies could also investigate how to counter neutralization strategies. Similar to Wilcox et al. (2009), the findings suggest that counterfeit products serve a value-expressive function for some consumers. Such consumers like the style and appearance, so they do not care whether products are counterfeits or whether there is a logo embedded. Theoretically, it would be interesting to examine whether consumers really "don't care," as they claim, or whether such claims are neutralization techniques. This study was restricted to Chinese consumers only. Previous research suggests that certain traditional Chinese cultural values support counterfeit consumption (Wan et al., 2009). This suggestion should encourage future researchers to examine whether the findings of this study would be observed in other cultures/countries. Consumers increasingly desire and value authenticity in the post-modern marketplace (Rose \& Woods, 2005; Beverland \& Farrelly, 2010; Yuan, Liu, Luo, Nguyen \& Yang, 2014). The fast surging demand for counterfeit products contests the notion of pursuing of authenticity in 
consumption, as consumers do not find authenticity in the counterfeit (Rose \& Wood; Liu, Yannopoulou, Bian \& Elliott, 2015). The data of this research does not reflect on the authenticity aspect of counterfeits, thus, further research investigating consumers' comparative responses to authenticity when probed as opposed to non-proved would be a valuable contribution. 


\section{References}

Ang, S. H., Cheng, P. S., Lim, E. A. C., \& Tambyah, S. K. (2001). Spot the difference: Consumer responses towards counterfeits. Journal of Consumer Marketing, 18(3), 219235.

Antonides, G., \& van Raaij, F. W. (1998). Consumer behaviour: A European perspective. Chichester: Wiley.

Assael, H. (2004). Consumer behavior-A strategic approach. Boston: Houghton Mifflin. Audi, R. (2012). Virtue ethics as a resource in business. Business Ethics Quarterly, 22(2), $273-291$.

Bamossy, G., \& Scammon, D. (1985). Product counterfeiting: Consumers and manufacturers beware. Advances in Consumer Research, 12(1), 334-340.

Banister, E. N., \& Hogg, M. K. (2004). Negative symbolic consumption and consumers' drive for self-esteem. European Journal of Marketing, 38(7), 850-868.

Bekir, I., El Harbi, S., \& Grolleau, G. (2013). How a luxury monopolist might benefit from the aspirational utility effect of counterfeiting? European Journal of Law and Economics, 36(1), 169-182.

Belk, R., Fischer, E., \& Kozinets, R. (2013). Qualitative consumer and marketing research. London: Sage.

Belk, R. W., Wallendorf, B. M., \& Sherry, J. F., Jr. (1989). The sacred and the profane in consumer behavior: Theodicy on the odyssey. Journal of Consumer Research, 16(1), 138.

Bersoff, D. M. (1999). Why good people sometimes do bad things: Motivated reasoning and unethical behaviour. Personality and Social Psychology Bulletin, 25(1), 28-39.

Bhal, K. T., \& Leekha, N. D. (2008). Exploring cognitive moral logics using grounded theory: The case of software piracy. Journal of Business Ethics, 81(3), 635-646. 
Bian, X. (2006). An examination of factors influencing the formation of the consideration Set and consumer purchase intention in the context of non-deceptive counterfeiting (Unpublished doctoral dissertation). University Of Glasgow, Glasgow, UK.

Bian, X., \& Moutinho, L. (2009). An investigation of determinants of counterfeit purchase consideration. Journal of Business Research, 62(3), 368-378.

Bian, X., \& Moutinho, L. (2011a). Counterfeit and branded products: Effects of counterfeit ownership. Journal of Product and Brand Management, 20(5), 379-393.

Bian, X., \& Moutinho, L. (2011b). The role of brand image, product involvement, and knowledge in explaining consumer purchase behaviour of counterfeits: Direct and indirect effects. European Journal of Marketing, 45(1/2), 191-216.

Bian, X., \& Veloutsou, C. (2007). Consumers' attitudes regarding non-deceptive counterfeit brands in the UK and China. Journal of Brand Management, 14(3), 211-222.

Bloch, P. H., Bush, R. F., \& Campbell, L. (1993). Consumer "accomplices" in product counterfeiting. Journal of Consumer Marketing, 10(4), 27-36.

Browne, K. (2005). Snowball sampling: Using social networks to research non-heterosexual women. International Journal of Social Research Methodology, 8(1), 47-60.

Chatzidakis, A., Hibbert, S., \& Smith, A. P. (2007). Why people don't take their concerns about fair trade to the supermarket: The role of neutralisation. Journal of Business Ethics, 74(1), 89-100.

Chaudhry, P. E., \& Walsh, M. G. (1996). An assessment of the impact of counterfeiting in international markets: The piracy paradox persists. Columbia Journal of World Business, 31(3), 34-49.

Cheung, W., \& Prendergast, G. (2006). Buyers' perceptions of pirated products in China. Marketing Intelligence \& Planning, 24(5), 446-462. 
Churchill, G. A. (1999). Marketing Research: Methodological foundations (7th ed.). London: Dryden Press.

Commuri, S. (2009). The impact of counterfeiting on genuine-item consumers' brand relationships. Journal of Marketing, 73(3), 86-98.

Crane, A. (1999). Are you ethical? Please tick yes or no? On researching ethics in business organizations. Journal of Business Ethics, 20(3), 237-248.

Durkheim, E. (1915). The elementary forms of the religious life. London: Allen \& Unwin.

Eisend, M., \& Schuchert-Güler, P. (2006). Explaining counterfeit purchases, a review and preview. Academy of Marketing Science Review, 12, 1-25.

Flick, U. (2007). Designing qualitative research. Los Angeles, CA: Sage Publications.

Foxman, E. R., Berger, P. W., \& Cote, J. A. (1992). Consumer brand confusion: A conceptual framework. Psychology and Marketing, 9(2), 123-141.

Foxman, E. R., Muehling, D. D., \& Berger, P. W. (1990). An investigation of factors contributing to consumer brand confusion. Journal of Consumer Affairs, 24(1), 170 189.

Furnham, A., \& Valgeirsson, H. (2007). The effect of life values and materialism on buying counterfeit products. Journal of Socio-Economics, 36(5), 677-685.

Garcia-Ruiz, P., \& Rodriguez-Lluesma, C. (2014). Consumption practices: A virtue ethics approach. Business Ethics Quarterly, 24(4), 509-531.

Gentry, J. W., Putrevu, S., Shultz, C. J., \& Commuri, S. (2001). How now Ralph Lauren? The separation of brand and product in a counterfeit culture. Advances in Consumer Research, 27(1), 258-265.

Gregory-Smith, D., Smith, A., \& Winklhofer, H. (2013). Emotions and dissonance in “ethical” consumption choices. Journal of Marketing Management, 29(11-12), 12011223. 
Grossman, G. M., \& Shapiro, C. (1988). Foreign counterfeiting of status goods. The Quarterly Journal of Economics, 103(1), 79-100.

Hirschman, E. C. (1986). Humanistic inquiry in marketing research: Philosophy, method and criteria. Journal of Marketing Research, 23(3), 237-249.

Hirschman, E. C., \& Holbrook, M. B. (1982). Hedonic consumption: Emerging concepts, methods, and propositions. Journal of Marketing, 46(3), 92-101.

Hoe, L., Hogg, G., \& Hart, S. (2003). Fakin' it: Counterfeiting and consumer contradictions In D. Turley \& S. Brown (Eds.), Proceedings of European Advances in Consumer Research (volume 6, pp. 60-67). Provo, UT: Association for Consumer Research.

Hukla, P., Banerjee, M., \& Adidam, P. T. (2010). Antecedents and consequences of consumer confusion: Analysis of the financial services industry. Advances in Consumer Research, 39, 292-297.

International Anti-Counterfeiting Coalition. (2014). Counterfeiting statistics. Retrieved from http://www.iacc.org/counterfeiting-statistics [Accessed: 24 November, 2014].

International Chamber of Commerce. (2004). A brief overview of counterfeiting. Retrieved from http://www.iacc.org/resources/Facts_on_fakes.pdf/ [Accessed: 28 August, 2011].

International Chamber of Commerce. (2013). Counterfeiting, piracy and smuggling in India-Effects and potential solutions. Retrieved from http://www.iccwbo.org/Advocacy-Codes-and-Rules/BASCAP/Internationalengagement-and-Advocacy/Country-Initiatives/Counterfeiting,-Piracy-and-Smugglingin-India---Effects-and-Potential-Solutions/ [Accessed: 10 December, 2013].

Jiang, L., \& Cova, V. (2012). Love for luxury, preference for counterfeits-A qualitative study in counterfeit luxury consumption in China. International Journal of Marketing Studies, 4(6), 1-9. 
Kapferer, J. (1995). Brand confusion: Empirical study of a legal concept. Psychology \& Marketing, 12(6), 551-569.

Katz, D. (1960). The functional approach to the study of attitudes. Public Opinion Quarterly, 24(2), 163-204.

Kim, H., \& Karpova, E. (2010). Consumer attitudes toward fashion counterfeits: Application of the theory of planned behavior. Clothing and Textiles Research Journal, 28(2), 7994.

Liao, C., \& Hsieh, I.-Y. (2013). Determinants of consumer's willingness to purchase graymarket smartphones. Journal of Business Ethics, 114(3), 409-424.

Lin, Y. C. (2011). Fake stuff: China and the rise of counterfeit goods. New York: Taylor and Francis.

Lu, L., \& Lu, C. (2010). Moral philosophy, materialism, and consumer ethics: An exploratory study in Indonesia. Journal of Business Ethics, 94(2), 193-210.

Malhotra, H. N. (2007). Marketing research: An applied orientation (5th ed.). Upper Saddle River, NJ: Pearson Education.

Mitchell, V., \& Papavassiliou, V. (1999). Marketing causes and implications of consumer confusion. Journal of Product \& Brand Management, 8(4), 319-342.

Nia, A., \& Zaichkowsky, J. (2000). Do counterfeits devalue the ownership of luxury brands? Journal of Product \& Brand Management, 9(7), 485-497.

Nill, A., \& Shultz II, C. J. (1996). The scourge of global counterfeiting. Business Horizons, $39(6), 37-43$.

Patton, M. Q. (1990). Qualitative evaluation methods. Thousand Oaks, CA: Sage.

Penz, E., \& Stöttinger, B. (2005). Forget the "real" thing-Take the copy! An explanatory model for the volitional purchase of counterfeit products. Advances in Consumer Research, 32, 568-575. 
Perez, M. E., Castaño, R., \& Quintanilla, C. (2010). Constructing identity through the consumption of counterfeit luxury goods. Qualitative Market Research: An International Journal, 13(3), 219-235.

Phau, I., Prendergast, G., \& Chuen, L. (2001). Profiling brand-piracy-prone consumers: An exploratory study in Hong Kong's clothing industry. Journal of Fashion Marketing and Management, 5(1), 45-55.

Phau, I., \& Teah, M. (2009). Devil wears (counterfeit) Prada: A study of antecedents and outcomes of attitudes towards counterfeits of luxury brands. Journal of Consumer Marketing, 26(1), 15-27.

Playle, S., VanAuken, B. (2003). Legal update. Brand Management, 10(6), 457-459.

Poddar, A., Foreman, J., Banerjee, S. (, \& Ellen, P. S. (2012). Exploring the Robin Hood effect: Moral profiteering motives for purchasing counterfeit products. Journal of Business Research, 65(10), 1500-1506.

Romani, S., Gistri, G., \& Pace, S. (2012). When counterfeits raise the appeal of luxury brands. Marketing Letters, 23(3), 807-824.

Ryan, R. M., \& Deci, E. L. (2000). Self-determination theory and the facilitation of intrinsic motivation, social development, and well-being. American Psychologist, 55(1), 68-78.

Shavitt, S. (1989). Products, personalities and situations in attitude functions: Implications for consumer behavior. Advances in Consumer Research, 16(1), 300-305.

Silverman, D. (2011). Interpreting qualitative data. London: Sage Publications.

Smith, B. M., Bruner, J. S., \& White, R. W. (1956). Opinions and personality. New York: Wiley.

Spiggle, S. (1994). Analysis and interpretation of qualitative data in consumer research. Journal of Consumer Research, 21(3), 491-503. 
Stöttinger, B., \& Penz, E. (2015). Concurrent ownership of brands and counterfeits: Conceptualization and temporal transformation from a consumer perspective. Psychology \& Marketing, 32(4), 373-391.

Swike, E., Thompson, S., \& Vasquez, C. (2008). Piracy in China. Business Horizons, 51(6), 493-500.

Sykes, G. M., \& Matza, D. (1957). Techniques of neutralization: A theory of delinquency. American Sociological Review, 22(6), 664-670.

Tang, F., Tian, V., \& Zaichkowsky, J. (2014). Understanding counterfeit consumption. Asia Pacific Journal of Marketing and Logistics, 26(1), 4-20.

Taylor, S., \& Borgan, R. (1984). Introduction to qualitative research methods: The search for meanings. New York: Wiley.

Tom, G., Garibaldi, B., Zeng, Y., \& Pilcher, J. (1998). Consumer demand for counterfeit goods. Psychology \& Marketing, 15(5), 405-421.

Turnbull, P.W., Leek, S., \& Ying, G. (2000). Customer Confusion: The Mobile Phone Market. Journal of Marketing Management, 16, 143-163.

Wan, W. W. N., Luk, C., Yau, O. H. M., Tse, A. C. B., Sin, L. Y. M., Kwong, K. K., \& Chow, R. P. M. (2009). Do traditional Chinese cultural values nourish a market for pirated CDs? Journal of Business Ethics, 88(1), 185-196.

Wee, C., Ta, S., \& Cheok, K. (1995). Non-price determinants of intention to purchase counterfeit goods. International Marketing Review, 12(6), 19-47.

Wilcox, K., Kim, H. M., \& Sen, S. (2009). Why do consumers buy counterfeit luxury brands? Journal of Marketing Research, 46(2), 247-259.

Yoo, B., \& Lee, S.-H. (2009). Buy genuine luxury fashion products or counterfeits? Advances in Consumer Research, 36(1), 280-286). 
Zaichkowsky, J. L. (2006). The psychology behind trademark infringement and counterfeiting. Mahwah, NJ: Lawrence Erlbaum Associates.

Bian, X., Haque, S., \& Smith, A. (2015). Social Power, Product Conspicuousness and the Demand for Luxury Brand Counterfeit Products. British Journal of Social Psychology, 54(1), 37-54.

Chatzidakis, A., Hibbert, S., \& Smith, A. P. (2007). Why People Don't Take Their Concerns about Fair Trade to the Supermarket: The Role of Neutralisation. Journal of Business Ethics, 74(1), 89-100.

Liu, M. J., Yannopoulou, N., Bian, X., \& Elliot, R. (2015). Perceptions of Authenticity within the Chinese Marketplace. Journal of Business Research, 68(1), 27-33.

Yuan, R. Z., Liu, M. J., Luo, J., Nguyen, B., \& Yang, F. K. (2014). A Critical Review of the Literature on Authenticity: Evolution and Future Research Agenda. International Journal of Service, Economics and Management, 6(4), 339-356.

Rose, R. L. \& Wood, S. L. (2005). Paradox and the Consumption of Authenticity through Reality Television. Journal of Consumer Research, 32, 284-96.

Beverland, M. B. \& Farrelly, F. J. (2010). The Quest for Authenticity in Consumption: Consumers' Purposive Choice of Authentic Cues to Shape Experienced Outcomes. Journal of Consumer Research, 36(5), 838-856. 
Table 1: Participants' information

\begin{tabular}{|c|c|c|c|c|c|}
\hline Respondent & Gender & Age & Education background & $\begin{array}{l}\text { Annual household } \\
\text { income (CNY) }\end{array}$ & $\begin{array}{l}\text { Type of counterfeit purchase } \\
\text { experience }\end{array}$ \\
\hline 1 & Female & 28 & Undergraduate Degree & Several million & Own and friend's experience \\
\hline 2 & Male & 25 & Undergraduate Degree & 600,000 & Own and friend's experience \\
\hline 3 & Male & $\begin{array}{l}\text { Not } \\
\text { specified }\end{array}$ & Undergraduate Degree & $150,000-200,000$ & Friend's experience \\
\hline 4 & Female & $\begin{array}{l}\text { Not } \\
\text { specified }\end{array}$ & Undergraduate Degree & Around 1 million & Own an d friend's experience \\
\hline 5 & Female & 35 & Postgraduate Degree & $\begin{array}{l}\text { Several hundred } \\
\text { thousands }\end{array}$ & $\begin{array}{l}\text { Relative and friend's } \\
\text { experience }\end{array}$ \\
\hline 6 & Male & $\begin{array}{l}\text { Not } \\
\text { specified }\end{array}$ & Undergraduate Degree & $40,000-50,000$ & Friends' experience \\
\hline 7 & Female & 22 & Senior High School & 90,000 & Own and friend's experience \\
\hline 8 & Female & 31 & Postgraduate Degree & $350,000-400,000$ & Own and friend's experience \\
\hline 9 & Male & 27 & Postgraduate Degree & Not specified & Own and friend's experience \\
\hline 10 & Female & $\begin{array}{l}\text { Not } \\
\text { specified }\end{array}$ & Undergraduate Degree & Not specified & Friend's experience \\
\hline 11 & Female & 26 & Undergraduate Degree & Average & Friend's experience \\
\hline 12 & Female & 27 & Postgraduate Degree & 300,000 & Own and friend's experience \\
\hline 13 & Female & 20 & Senior High School & $\begin{array}{l}400,000 \text { to } 1 \\
\text { million }\end{array}$ & Own and friend's experience \\
\hline 14 & Female & $\begin{array}{l}\text { Not } \\
\text { specified }\end{array}$ & Undergraduate Degree & 100,000 & $\begin{array}{l}\text { Own, parents and relative's } \\
\text { experience }\end{array}$ \\
\hline 15 & Female & $\begin{array}{l}\text { Not } \\
\text { specified }\end{array}$ & Undergraduate Degree & More than 1 million & $\begin{array}{l}\text { Own, mother and friend's } \\
\text { experience }\end{array}$ \\
\hline 16 & Female & $\begin{array}{l}\text { Not } \\
\text { specified }\end{array}$ & Undergraduate Degree & $120,000-150,000$ & $\begin{array}{l}\text { Own, relative and friend's } \\
\text { experience }\end{array}$ \\
\hline
\end{tabular}


Figure 1: Anatomy of a typical episode

\section{Motivations}

Enhanced self-image

- Desired social identity

- Consumer hierarchy

"Thrill of the hunt"

Part of a "secret society"

Genuine interest

Saving money

\section{Neutralizations}

Denial of responsibility

Denial of the victim

Appealing to higher

loyalties

\section{Outcomes}

\section{Found out by peers:}

Self-conscious emotions:

- Embarrassment/shame

- Damage to self-image

\section{Got away with it:}

Enhanced self-image:

- Associated with desirable brands

Money saved at expense of time

Enjoyment

Satisfaction

\section{Self-declaration:}

Enhanced self-image:

- Being knowledgeable

- A wise consumer 